\title{
Effects of Cytokine-Induced Neutrophil Chemoattractants (CINCs) on Shape Change, Adhesiveness and Phagocytosis of Rat Neutrophils
}

\author{
Maher Al-Mokdad, ${ }^{*}$ Futoshi Shibata, and Hideo NaKagawa \\ Department of Physiological Chemistry, Faculty of Pharmaceutical Sciences, Toyama Medical and Pharmaceutical \\ University, 2630 Sugitani, Toyama 930-01, Japan. Received March 27, 1997; accepted May 8, 1997
}

\begin{abstract}
Rat cytokine-induced neutrophil chemoattractants (CINC)-1, $-2 \alpha,-2 \beta$ and -3 belong to $\alpha$-chemokines and are known to be potent chemoattractants for rat neutrophils in vivo and in vitro. In this study, the abilities of CINCs to affect several functions of rat neutrophils are estimated. All CINCs at a concentration of $10^{-8} \mathrm{M}$ induced the polarization of rat neutrophils. The adhesion of each CINC-treated neutrophil to fibrinogen significantly increased, reaching a maximal adhesion at $10^{-8} \mathrm{M}$ of each CINC. The CINCs enhanced the phagocytosis of heat-killed yeast cells by neutrophils in a dose-dependent manner. In contrast, CINCs did not induce the production of reactive nitrogen intermediates. The results suggest that CINCs play a significant role in neutrophil infiltration and phagocytosis at inflammatory sites in rats.
\end{abstract}

Key words neutrophil function; cytokine-induced neutrophil chemoattractant; chemokine; neutrophil adhesion; phagocytosis; polarization

The hallmark of inflammation is the migration, accumulation, and activation of leukocytes at the site of injury. ${ }^{1)}$ Leukocyte migration from the blood into tissue is a complex phenomenon including the endothelial adhesion and transendothelial migration of leukocytes. The accumulation of leukocytes at inflammatory sites is due in part to the effect of neutrophil-/monocyte-specific chemokines. ${ }^{2)}$ The chemokines are divided into two subfamilies, $\alpha$ - and $\beta$-chemokines, as defined by the spacing of the first two cysteines in a highly conserved four-cysteine motif. Recently, lymphotactin, a member of a new class of chemokines with preferential effects on lymphocytes, has been characterized. ${ }^{3)}$ Cytokine-induced neutrophil chemoattractants (CINCs) and macrophage inflammatory protein (MIP)- 2 are members of the $\alpha$-chemokine family. We have purified four CINCs (CINC-1, $-2 \alpha,-2 \beta$ and CINC-3/rat MIP-2) from the conditioned medium of a rat granulation-tissue culture. ${ }^{4)}$ CINC- $2 \alpha$ and CINC- $2 \beta$ differ only in the sequence of carboxy-terminal three amino acid residues. ${ }^{4)}$ None of the CINCs clearly correspond to any of human GRO- $\alpha, \beta$ and $\gamma$, though the CINCs are the rat counterparts of the GRO proteins on the basis of the similarities of amino acid sequences between CINCs and GRO proteins. ${ }^{4)}$ In previous studies using recombinant CINCs, we demonstrated that each CINC induced neutrophil chemotaxis in vitro and in vivo, increased intracellular $\mathrm{Ca}^{2+}$ concentration, and released cathepsin $\mathrm{G}$ from azurophil granules of rat neutrophils. ${ }^{5)}$ In addition, desensitization experiments suggested the presence of two putative receptors mediating the activities of CINCs for rat neutrophils. ${ }^{5,6)}$

The present studies are a further investigation of the biological activities of recombinant CINCs on rat neutrophils. We report here that CINCs stimulate neutrophils to cause shape change (polarization), increased adhesiveness, and increased phagocytosis toward heatkilled yeast cells, though no effect was detected on the nitrite production.

\section{MATERIALS AND METHODS}

Purification of Recombinant CINCs Recombinant CINC-1, $-2 \alpha,-2 \beta$ and $-3 /$ rat MIP-2 were purified from Escherichia coli JM109 carrying expression vectors as described previously, ${ }^{5,7)}$ and were used throughout the present studies.

Isolation of Rat Neutrophils Neutrophils were collected from the rat peritoneal cavities $16 \mathrm{~h}$ after the intraperitoneal injection of Krebs-Ringer bicarbonate solution containing $1 \%(\mathrm{w} / \mathrm{v})$ casein $(120 \mathrm{ml} / \mathrm{kg}$ body weight). Neutrophils were washed two times with Gey's balanced salt solution (GBSS) and then suspended in RPMI-1640 medium at a concentration of $10^{7}$ cells $/ \mathrm{ml}$.

Polarization Analysis The effect of CINCs on neutrophil shape change was investigated as reported by Lomas et al. ${ }^{8)}$ Neutrophils $\left(1 \times 10^{7} \mathrm{cells} / \mathrm{ml}\right)$ were incubated with each CINC at a concentration of $10^{-8} \mathrm{M}$ for $2 \mathrm{~min}$ prior to fixation with 10 volumes of $2 \%(\mathrm{v} / \mathrm{v})$ formaldehyde. In another experiment, formyl-methionylleucyl-phenylalanine (fMLP), a positive control, was added to the neutrophil suspension at a final concentration of $10^{-8} \mathrm{M}$ after the addition of the CINCs, and the suspension was left at room temperature for another hour before fixation. Polarization was measured by flow cytometry $\left(\right.$ Epics $^{\circledR}$-profile II analyzer, Coulter cooperation).

Adhesion Assay The assay was performed as described by Devi et al. ${ }^{1)}$ In order to provide a substrate for neutrophil binding, 96-well flat-bottom plates were coated with $25 \mu \mathrm{l}$ of fibrinogen solution $(2 \mathrm{mg} / \mathrm{ml}$ phosphatebuffered saline) (PBS) for $90 \mathrm{~min}$ at room temperature. Plates were washed three times with Hank's balanced salt solution (HBSS) containing $10 \mathrm{~mm}$ HEPES ( $\mathrm{pH} 7.3$ ) and $0.5 \%(\mathrm{w} / \mathrm{v})$ bovine serum albumin (BSA). Rat neutrophils were treated with different concentrations of each CINC at $37^{\circ} \mathrm{C}$ for $30 \mathrm{~min}$, and the neutrophil suspension $(5 \times$ $10^{5}$ cells/well) was added to the fibrinogen-coated well. After incubation at $37^{\circ} \mathrm{C}$ for $30 \mathrm{~min}$, plates were washed 5 times with the same buffer. Two hundred microliters of 
the buffer without BSA was added, followed by $10 \mu \mathrm{l}$ of the 3-[4,5-dimethylthiazol-2-yl]-2,5-diphenyltetrazolium bromide (MTT) $(5 \mathrm{mg} / \mathrm{ml})$. This mixture was incubated for $4 \mathrm{~h}$ at $37^{\circ} \mathrm{C}$. The supernatant was very carefully removed and $100 \mu 1$ of acid isopropanol $(2 \mathrm{mM} \mathrm{HCl})$ was added to the cells in order to solubilize the formozan crystals. The absorbance of each well was then read at $595 \mathrm{~nm}$ using a microplate reader (model 450; Bio-Rad Laboratories).

Phagocytosis Assay Different concentrations of CINCs in $0.3 \mathrm{ml}$ of neutrophil suspension $\left(10^{7}\right.$ cells $\left./ \mathrm{ml}\right)$ were incubated with $0.6 \mathrm{ml}$ of a heat-killed yeast cell suspension $\left(1 \times 10^{6}\right.$ cells $\left./ \mathrm{ml}\right)$ at $37^{\circ} \mathrm{C}$ for $30 \mathrm{~min}$. After centrifugation, the cell pellets were collected. Staining with Giemsa was performed after fixation with methanol, and the phagocytic index was determined. The phagocytic index was defined as the percent positive ingestion multiplied by the average number of ingested yeast cells per cell.

Nitrite Assay Neutrophils $\left(5 \times 10^{5}\right.$ cells $\left./ \mathrm{ml}\right)$ were cultured in RPMI-1640 containing 10\% fetal calf serum for $2 \mathrm{~h}$ at $37^{\circ} \mathrm{C}$ before use. The medium was replaced with $200 \mu \mathrm{l}$ of fresh medium and the cells were incubated with chemoattractants at concentrations of $10^{-9} \mathrm{M}-10^{-7} \mathrm{M}$ for $20 \mathrm{~h}$ at $37^{\circ} \mathrm{C}$. The nitrite concentration of the conditioned medium was measured as described by Ding et al. ${ }^{9)}$ The conditioned medium $(100 \mu \mathrm{l})$ was incubated with an equal volume of Greiss reagent $(1 \%$ sulfanilamide, $0.1 \%$ naphthylethylene diamine dihydrochloride, and $2.5 \% \mathrm{H}_{3} \mathrm{PO}_{4}$ ) at room temperature for $10 \mathrm{~min}$. The absorbance at $550 \mathrm{~nm}$ was determined using a microplate reader. Serial dilutions of $100 \mu \mathrm{M}$ of sodium nitrite were used to establish a standard curve.

\section{RESULTS}

Polarization At a concentration of $10^{-8} \mathrm{M}$ all CINCs induced the polarization of neutrophils above the negative control (Fig. 1). The effects of CINCs on the shape change of neutrophils were comparable with those induced by the same concentration of IMLP, a positive control. The effect on shape change was more clear when neutrophils were treated with a combination of IMLP and each CINC.

Adhesion to Fibrinogen To estimate the contribution of CINCs in the adhesiveness of neutrophils, the adhesion of CINC-treated neutrophils to fibrinogen was evaluated. In comparison with non-stimulated neutrophils, treatment with CINCs significantly enhanced the binding of neutrophils to fibrinogen (Fig. 2). The adhesion was maximal when neutrophils were treated with each CINC at a concentration of $10^{-8} \mathrm{M}$, and CINC-1, CINC- $2 \alpha$, CINC-2 $\beta$ and CINC-3 increased the adhesion 5.9, 3.7, 3.6 and 4.7 -fold, respectively. The adhesion induced by CINC-1 at a concentration of $10^{-8} \mathrm{M}$ was comparable with that induced by the same concentration of fMLP.

Phagocytosis The effect of CINCs on phagocytosis toward heat-killed yeast cells was investigated. All CINCs caused concentration-dependent increases in the phagocytosis of heat-killed yeast cells by neutrophils (Table 1). In comparison with the control, the phagocytic activities of neutrophils treated with CINC-1, CINC-2 $\alpha$, CINC- $2 \beta$ and CINC-3 increased 2.2, 1.8, 2.1 and 2-fold, respectively.

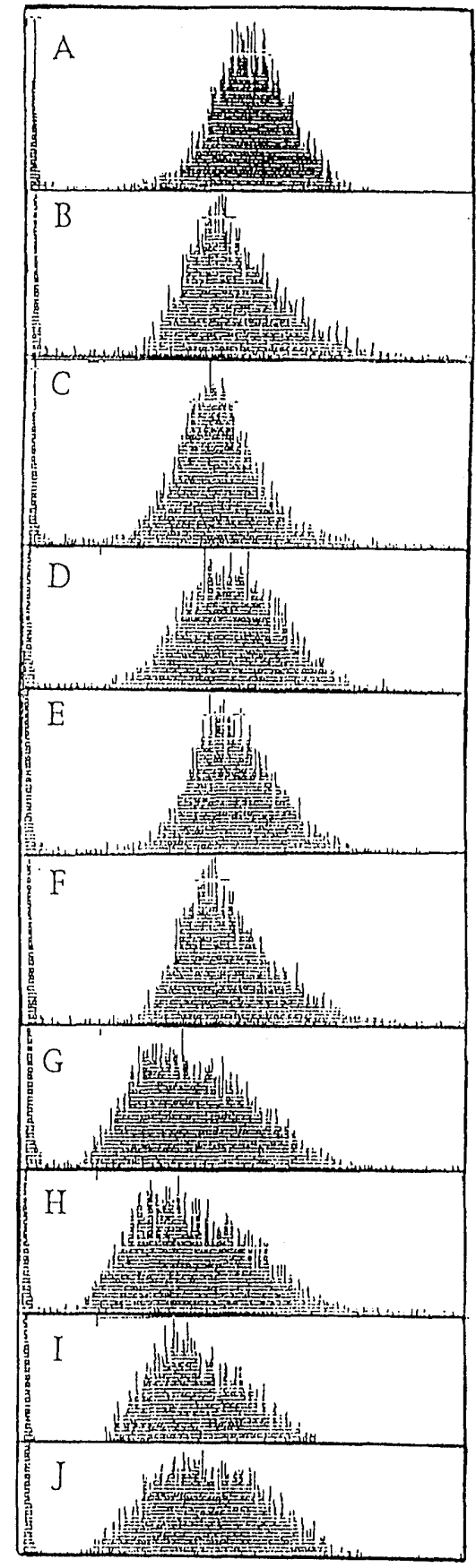

Fig. 1. Polarization of Neutrophils Stimulated with CINCs

Rat neutrophils $\left(1 \times 10^{7}\right.$ cells $\left./ \mathrm{ml}\right)$ were incubated with each $\mathrm{CINC}$ at a concentration of $10^{-8} \mathrm{M}$ for $2 \mathrm{~min}$ prior to fixation. A, negative control; $\mathrm{B}, \mathrm{fMLP}$; $\mathrm{C}, \mathrm{CINC}-1 ; \mathrm{D}, \mathrm{CINC}-2 \alpha ; \mathrm{E}, \mathrm{CINC}-2 \beta ; \mathrm{F}, \mathrm{CINC}-3$. In the following experiments, at 2 min after the addition of the CINCs, the fMLP was added to the neutrophil suspensions at a final concentration of $10^{-8} \mathrm{M}$, and the suspensions were left at room temperature for another hour before fixation. Polarization was measured by flow cytometry. G, CINC-1 with fMLP; H, CINC- $2 \alpha$ with fMLP; I, CINC-2 $\beta$ with IMLP; J, CINC-3 with fMLP.

Production of Nitrite We examined the ability of CINCs to stimulate the production of reactive nitrogen intermediates (RNI) by neutrophils as measured by the production of nitrite. Treatment of neutrophils with different concentrations of CINCs resulted in no induction of RNI production from stimulated neutrophils (data are not shown). In contrast, the treatment of neutrophils with $10^{-8} \mathrm{M}$ of fMLP resulted in a 1.6-fold higher level of nitrite production by non-stimulated neutrophils. The present findings indicate that CINCs are incapable of generating 


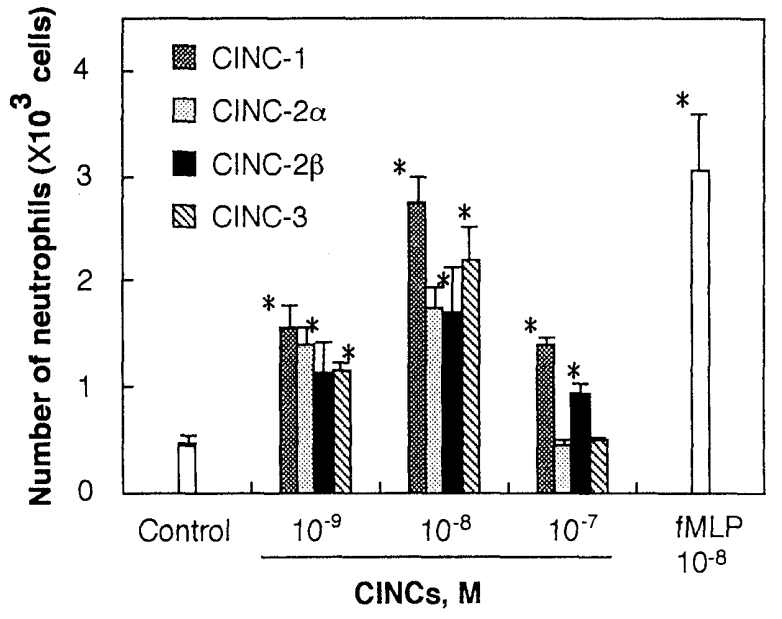

Fig. 2. Effect of CINCs on the Neutrophil Adhesion to Fibrinogen

Rat neutrophils treated with CINCs at $37^{\circ} \mathrm{C}$ for $30 \mathrm{~min}$ were added to fibrinogen-coated plates $\left(5 \times 10^{5}\right.$ cells/well). After incubation at $37^{\circ} \mathrm{C}$ for $30 \mathrm{~min}$, the number of neutrophils which adhered to fibrinogen was determined. Each point represents the means \pm S.E. of six determinations. Values are significantly different from the control: $* p<0.01$.

Table 1. Effect of CINCs on Phagocytosis of Heat-Killed Yeast Cells by Neutrophils

\begin{tabular}{|c|c|c|}
\hline $\begin{array}{c}\text { CINCs, } \\
\mathrm{M}\end{array}$ & $\begin{array}{c}\text { Phagocytosis }{ }^{a)} \\
(\%)\end{array}$ & Phagocytic index ${ }^{b}$ \\
\hline \multicolumn{3}{|l|}{ CINC-1 } \\
\hline $10^{-10} \mathrm{M}$ & $16.3 \pm 4.5$ & $27.7 \pm 6.5$ \\
\hline $10^{-9} \mathrm{M}$ & $17.7 \pm 2.0$ & $25.0 \pm 2.3$ \\
\hline $10^{-8} \mathrm{M}$ & $24.3 \pm 4.8$ & $30.0 \pm 9.4$ \\
\hline $10^{-7} \mathrm{M}$ & $23.3 \pm 3.5$ & $34.0 \pm 4.1^{*}$ \\
\hline \multicolumn{3}{|l|}{ CINC- $2 \alpha$} \\
\hline $10^{-10} \mathrm{M}$ & $18.7 \pm 4.8$ & $29.0 \pm 8.0$ \\
\hline $10^{-9} \mathrm{M}$ & $22.0 \pm 2.1$ & $30.0 \pm 1.0^{*}$ \\
\hline $10^{-8} \mathrm{M}$ & $28.0 \pm 6.2$ & $30.0 \pm 8.1$ \\
\hline $10^{-7} \mathrm{M}$ & $32.0 \pm 3.5$ & $45.0 \pm 4.9^{*}$ \\
\hline \multicolumn{3}{|l|}{ CINC- $2 \beta$} \\
\hline $10^{-10} \mathrm{M}$ & $21.0 \pm 2.6$ & $30.0 \pm 7.0$ \\
\hline $10^{-9} \mathrm{M}$ & $17.0 \pm 2.6$ & $32.7 \pm 7.0$ \\
\hline $10^{-8} \mathrm{M}$ & $26.0 \pm 3.5$ & $35.2 \pm 2.5^{*}$ \\
\hline $10^{-7} \mathrm{M}$ & $28.0 \pm 3.1$ & $38.3 \pm 3.3^{*}$ \\
\hline \multicolumn{3}{|l|}{ CINC-3 } \\
\hline $10^{-10} \mathrm{M}$ & $14.0 \pm 3.5$ & $17.5 \pm 4.4$ \\
\hline $10^{-9} \mathrm{M}$ & $15.7 \pm 3.0$ & $20.0 \pm 5.0$ \\
\hline $10^{-8} \mathrm{M}$ & $26.0 \pm 4.5$ & $30.0 \pm 1.3^{*}$ \\
\hline $10^{-7} \mathrm{M}$ & $32.0 \pm 4.0$ & $46.0 \pm 4.9^{*}$ \\
\hline Control & $14.0 \pm 1.5$ & $21.0 \pm 2.5$ \\
\hline
\end{tabular}

a) Rat neutrophil suspensions $\left(5 \times 10^{5}\right.$ cells $\left./ \mathrm{ml}\right)$ containing different concentrations of CINCs were incubated with heat-killed yeast cells $\left(1 \times 10^{6}\right.$ cells $\left./ \mathrm{ml}\right)$ in a total volume of $0.9 \mathrm{ml}$ at $37^{\circ} \mathrm{C}$ for $30 \mathrm{~min}$. After incubation, phagocytosis was microscopically assayed. The values represent the means \pm S.E. of 3 determinations. b) Phagocytic index is the percentage of neutrophils with particles ingested, multiplied by the average number of particles ingested per cell. Values are significantly different from the control: $* p<0.01$.

extracellular RNI detectable with the method utilized.

\section{DISCUSSION}

CINCs belong to the $\alpha$-chemokine family, which includes IL-8, growth regulated/melanoma growth stimulatory activity (GRO/MGSA) and MIP-2. CINCs are chemoattractants for neutrophils, as evidenced by both in vitro and in vivo studies. ${ }^{4,5)}$ Although many studies described the biological activities of $\alpha$-chemokines, little is known about the activities of CINCs on their target cells. The most studied $\alpha$-chemokine, IL- 8 , acts mainly on neutrophils, and induces chemotaxis and adhesion to endothelial cells. ${ }^{10,11)}$ In neutrophils, IL-8 binds to type $\mathrm{A}$ and type $\mathrm{B}$ receptors, induces $\mathrm{Ca}^{2+}$-transients, and stimulates the release of elastase as well as vitamin $\mathrm{B}_{12}$-binding protein. ${ }^{10-13)}$ The present study demonstrated that CINCs can also activate target cells. It is thought that the morphological polarization of neutrophils affects the ability to migrate through the vascular endothelium. The increasing volume of neutrophils, which is accompanied by neutrophil migration in vitro, suggested that the volume change may contribute to the migratory process itself. ${ }^{14)}$ In this study, the exposure of neutrophils to each CINC induced a shape change of the neutrophils (Fig. 1). It had previously been reported that the effect of IL-8 on the shape change of human neutrophils reached a maximum in approximately $30 \mathrm{~s}$, and reverted to prestimulation level within $1.5-2$ min. ${ }^{15)}$ In our experiments, the shape change of neutrophils occurred $2 \mathrm{~min}$ after exposure to CINCs, indicating that shape change is a very early response to stimulation by chemotactic factors.

An essential process for the migration of neutrophils from the circulation into an inflammatory site is the enhanced adhesion of neutrophils to the vascular endothelium and matrix proteins. CINCs are capable of inducing neutrophil adhesion to fibrinogen, as shown in Fig. 2. Our observations are in good agreement with the finding that IL-8 at a concentration of $5 \times 10^{-8} \mathrm{M}$ increased the binding of neutrophils to fibrinogen immobilized on plastic substrates by an average of 4.3 -fold. ${ }^{16)}$ Since the protocol of the adhesion assay includes rather vigorous washing steps, the neutrophils detected in our experiments may represent the neutrophils exerting very strong adhesive interactions. Despite the relatively low adhesion of neutrophils to fibrinogen, it may be physiologically relevant. It has been suggested that $\mathrm{CD} 11 \mathrm{~b} / \mathrm{CD} 18$ functions as a receptor not only for $\mathrm{C} 3 \mathrm{bi}$, but also for fibrinogen, because the binding of neutrophils to fibrinogen-coated surfaces was blocked by monoclonal antibodies against complement receptor type 3 (CR3; $\mathrm{CD} 1 \mathrm{~b} / \mathrm{CD} 18)$, a molecule identified as a receptor for complement protein fragment $\mathrm{C} 3 \mathrm{bi} .{ }^{17)} \mathrm{A}$ significant increase in $\mathrm{CD} 11 \mathrm{~b} / \mathrm{CD} 18$ receptor level on neutrophils was found when rat $\mathrm{KC} / \mathrm{CINC}-1$ was added to rat whole blood. ${ }^{18)}$ The results and our data suggest that CINCs modulate neutrophil adherence by affecting the expression of adhesion molecules, including CD11b/CD18.

Phagocytosis is an important function of neutrophils in the host defense against infectious organisms. The phagocytic response is a complex, multistep, and probably multibranched process. ${ }^{19)}$ In the present study, the effect of CINCs on the phagocytosis of heat-killed yeast cells by neutrophils was investigated. As shown in Table 1, CINCs enhanced the phagocytosis of heat-killed yeast cells by neutrophils in a dose-dependent manner, suggesting that CINCs may be involved in the elimination of microorganisms during acute inflammation. We previously demonstrated that CINCs stimulated the release of cathepsin $G$ from neutrophils in a dose-dependent 
manner. ${ }^{5)}$ Similarly, in the present study we found that CINCs also stimulate the release of $\beta$-glucuronidase and myeloperoxidase, constituents of azurophil granules (data are not shown). The results indicate that CINCs induce the exocytosis of azurophil granules from rat neutrophils.

Reactive nitrogen intermediates (RNI) are derived from nitric oxide (NO) and include nitrite and nitrate. RNI are secretory products of activated macrophages, ${ }^{20)}$ but are also secreted by numerous cell types, including neutrophils. ${ }^{21)}$ Others, however, have not detected the formation of RNI by neutrophils. ${ }^{22)}$ In this study we investigated the ability of CINCs to induce the production of nitric oxide/nitrite. No significant amount of nitrite was detected following the activation of neutrophils with CINCs.

In summary, CINCs caused a neutrophil shape change (polarization), adhesiveness, exocytosis and increased phagocytic activity toward heat-killed yeast cells. However, CINCs failed to induce the release of reactive nitrogen intermediates. Our results suggest that CINCs play an important role in the processes of rat inflammation.

\section{REFERENCES}

1) Devi S., Laning J., Luo Y., Dorf, M. E., J. Immunol., 154, 5376-5383 (1995).

2) Oppenheim J. J., Zachariae C. O., Mukaida N., Matsushima K., Annu. Rev. Immunol., 9, 617-648 (1991).

3) Kennedy J., Kelner G. S., Kleyensteuber S., Schall T. J., Weiss M. C., Yssel H., Scheider P. V., Cocks B. G., Bacon K. B., Zlotnik A., J. Immunol., 155, 203-209 (1995).

4) Nakagawa H., Komorita N., Shibata F., Ikesue A., Konishi K., Fujioka M., Kato. H., Biochem. J., 301, 545-550 (1994).

5) Shibata F., Konishi K., Kato H., Komorita N., AL-mokdad M., Fujioka M., Nakagawa H., Eur. J. Biochem., 231, 306-311 (1995).
6) AL-mokdad M., Shibata F., Nakagawa H., Biol. Pharm. Bull., 19, 879-881 (1996).

7) Konishi K., Takata Y., Watanabe K., Date T., Yamamoto M., Murase A., Yoshida H., Suzuki T., Tsurufuji S., Fujioka M., Cytokine., 5, 506-511 (1993).

8) Lomas D. A., Stone S. R., Llewellyn-Jones C., Keogan M. T., Wang Z. M., Rubin H., Carrell R. W., Stockley, R. A., J. Biol. Chem., 270, 23437-23443 (1995).

9) Ding A. H., Nathan C. F., Stuehr D. J., J. Immunol., 141, 2407-2412 (1988).

10) Baggiolini M., Walz A., Kunkel S. L., J. Clin. Invest., 84, 1045-1049 (1989).

11) Moser B., Clark-Lewis I., Zwahlen R., Baggiolini M., J. Exp. Med., 171, 1797-1802 (1990).

12) LaRosa G. J., Thomas K. M., Kaufmann M. E., Mark R., White M., Taylor L., Gray G., Witt D., Navarro J., J. Biol. Chem., 267, 25402-25406 (1992).

13) Norgauer J., Krutmann J., Dobos G. J., Traynor-Kaplan A. E., Oades Z. G., Schraufstatter I. U., J. Invest. Dermatol., 102, 310-314 (1994).

14) Rosengren S., Henson P. M., Worthen G. S., Am. J. Physiol., 267, 1623-1633 (1994).

15) Thelen M., Peveri P., Kernen P., Vinzeng T. V., Walz A., Baggiolini M., Faseb. J., 2, 2702-2706 (1988).

16) Detmers P. A., Lo S. K., Olsen-Egbert E., Walz A., Baggiolini M., Cohn Z. A., J. Exp. Med., 171, 1155-1162 (1990).

17) Wright S. D., Weitz J. I., Huang A. J., Levin S. M., Silverstien S. C., Loike J. D., Proc. Natl. Acad. Sci. U.S.A., 85, 7734-7738 (1988)

18) Frevert C. W., Huang S., Danaee H., Paulauskis J. D., Kobzik L., J. Immunol., 154, 335-344 (1995).

19) Ishibashi Y., Yamashita T., Infect. Immun., 38, 825-833 (1982).

20) Stuehr D. J., Marletta M. A., Proc. Natl. Acad. Sci. U.S.A., 82, $7738-7742$ (1985).

21) Wright C. D., Mulsch A., Busse R., Osswald H., Biochem. Biophys. Res. Commun., 160, 813-819 (1989).

22) Rimele T. J., Sturm R. J., Adams L. M., Henry D. E., Heaslip R. J., Weichman B. M., Grimes D., J. Pharmacol. Exp. Ther., 245, 102-111 (1988). 